\title{
Promoting factors of physical and mental development in early infancy: a comparison of preterm delivery/low birth weight infants and term infants
}

\author{
Kaori Hayashida $\cdot$ Mikiya Nakatsuka
}

Received: 26 September 2013/Accepted: 1 November 2013/Published online: 28 November 2013

(C) The Japanese Society for Hygiene 2013

\begin{abstract}
Objective The aim of this study was to assess correlations between various factors and the physical and mental development of 4-month-old infants using a multi-faceted evaluation approach.

Methods A total of 1,402 self-administered questionnaires were distributed to consenting mothers of infants who had undergone a 4-month health checkup in Hiroshima prefecture, Japan. The questionnaires included items from the Japan Child and Family Research Institute Child Rearing Support Questionnaire and the KIDS type A test. Of the 421 completed questionnaires on mother-child pairs that were returned, 318 met the inclusion criteria and were eligible for further analysis.

Results Comparison between infants in a preterm delivery or low birth weight (LBW) group (preterm and/or LBW group; $n=31$ ) and a term delivery appropriate-weight for date (AFD) infant group (term AFD group; $n=287$ ) revealed that the preterm and/or LBW group had significantly higher mother child-rearing anxiety and difficult baby scores, along with significantly lower infant development and motor skill scores. Within the term AFD group, infants of primiparous mothers had significantly higher scores for motor skill and sociability with adults than those of multiparous mothers. Language
\end{abstract}

K. Hayashida $(\bowtie) \cdot$ M. Nakatsuka

Graduate School of Health Sciences, Okayama University, 2-5-1 Shikata, Kita-ku, Okayama, Okayama 700-8558, Japan e-mail: kaori@heisei-u.ac.jp

M. Nakatsuka

e-mail: mikiya@cc.okayama-u.ac.jp

K. Hayashida

Fukuyama Heisei University, 117-1 Kami-iwanari-shoto,

Miyuki-cho, Fukuyama, Hiroshima 720-0001, Japan comprehension scores were significantly higher in infants that were exclusively breast-fed than those formula-fed or combined breast-fed and formula-fed. Verbalization scores of infants whose mothers worked were significantly higher than those of infants whose mothers did not work. Infants with siblings aged $<4$ years exhibited significantly lower scores for motor skills, verbalization, and sociability with adults than infants without siblings or with siblings aged at least 5 years. In particular, we found that a mother's childrearing anxiety was related to many areas of infant development.

Conclusions Evaluating the absence or presence of such factors and conducting preventive treatment could promote healthy infant development.

Keywords Child-rearing anxiety · Early infancy . Infant development $\cdot$ Low birth weight $\cdot$ Preterm delivery

\section{Introduction}

Many different factors influence the physical and mental development of children. It has been reported that psychological stress [1], depression [1, 2], anxiety [1, 2], and anger [2] experienced by the mother during pregnancy may affect child development. Exposure to environmental risk factors, such as mercury [3] and cadmium [3], as well as smoking [4] and alcohol consumption [5] during pregnancy are also known to affect child development.

In developing countries, malnutrition of infants has been reported to affect child development [6]. In contrast, in developed countries, preterm delivery, low birth weight (LBW), maternal depression [7], and motherinfant interactions [8], such as an inadequate parenting 
attitude and lack of affection for the infant, have been reported to affect child development. It has also been found that child-rearing environmental factors, such as family and overcrowding in daycare centers, affect development [9].

Various indices have been designed to evaluate child development. In most previous studies, however, child development was evaluated based on only one aspect of observation. The Denver Developmental Screening Test [10] was devised to provide a simple screening method for evidence of slow development in infants and preschool children. The Brazelton Neonatal Behavioral Assessment Scale [11] measures neonatal behavioral development, while the Bayley Scales of Infant Development [12] measures mental and motor development and tests the behavior of infants aged 1-42 months.

In the study reported here, we used the Kinder Infant Development Scale (KIDS) test to assess infant development. The KIDS test assesses six aspects affecting infant development, namely, physical ability, verbal ability, cognitive abilities, social behavior of adults, social behavior of children, and manipulation [13]. It was developed in Japan in 1989 and has been used for multifaceted assessment of infant development. It was standardized using data on 6,000 infants, and its validity and reliability have been proven in healthy infants and infants with special needs [14]. An additional benefit is that a mother without special knowledge can complete the test simply by observing her infant's behavior.

Based on the results of their study using the KIDS, Cheng et al. concluded that supportive co-parenting and maternal cognitive stimulation greatly influence child development [15]. However, these authors evaluated 9-month-old infants, which is a relatively late phase of development; consequently, the study did not distinguish between term infants and preterm or low birth weight (LBW) infants. At 9 months, intervention for promoting development can be difficult because the mother-child relationship has been established. Therefore, factors that impede infant development must be detected earlier. In addition, when compared with term infants, preterm infants are more likely to exhibit problems in language development [16], while LBW infants are more likely to exhibit delayed motor and social development [17]. Therefore, preterm and LBW infants should be examined separately from appropriate-weight for date (AFD) infants. Consequently, we conducted a multi-faceted assessment of the development of 4-month-old infants using KIDS and compared the development of term infants with that of preterm and/or LBW infants. We also investigated factors that may influence the development of healthy infants.

\section{Materials and methods}

Between July 2010 and August 2011, we distributed 1,402 self-administered questionnaires to consenting mothers living in Hiroshima prefecture, Japan, whose infants had undergone the 4-month-old infant health checkup. The mothers were asked to complete the questionnaires at home and return them by post. This study was conducted with the approval of the Ethics Committee of the Graduate School of Health Sciences, Okayama University.

The survey investigated the following aspects: (1) mother's basic attributes (age, childbirth history, employment), (2) health during pregnancy and type of delivery, (3) maternal stress during pregnancy up to the present, (4) infant's basic attributes (sex, age, and weight at birth and at the 1- and 4-month infant health checkups), (5) child-rearing state, (6) child-rearing problems experienced by the mother and anxiety, (7) family function, and (8) household's economic state. Stress levels were self-assessed on a scale from 0 (= "not stressed at all") to 10 (= "very stressed").

Four of the six subscales of the Japan Child and Family Research Institute Child Rearing Support Questionnaire, namely, "mothers' feeling of child-rearing difficulty," "child-rearing anxiety," "family function state," and "difficult baby," were used to evaluate factors possibly related to the degree of the mother's child-rearing anxiety. The two items excluded were "husband poor mental and physical condition" and "child mental and physical state." KIDS type A, which can be used to evaluate healthy infants aged from 1 to 11 months, was used to assess infant development state.

\section{Statistical analysis}

The SPSS statistical program (ver. 18.0; SPSS Inc., Chicago, IL) was used to perform the statistical analyses. Student's $t$ test was used to compare continuous variables among groups, and the chi-squared test was used to compare categorical variables. The Mann-Whitney $U$ test or the Kruskal-Wallis test was used to compare median values of non-continuous variables in the KIDS and childrearing support questionnaire scores. A $p$ value of $<0.05$ was considered to be statistically significant.

\section{Results}

Of the 1,402 self-administered questionnaires that were distributed to mothers, 421 completed questionnaires on mother-child pairs (response rate $30.0 \%$ ) were returned. Questionnaires were excluded from subsequent analysis if an individual other than the mother completed the ques- 
Table 1 Medical background of responders

\begin{tabular}{|c|c|c|c|c|c|c|}
\hline \multirow[t]{2}{*}{ Clinical characteristics } & \multirow{2}{*}{$\begin{array}{l}\text { Preterm/LBW delivery } \\
(n=31)\end{array}$} & \multirow{2}{*}{$\begin{array}{l}\text { Term AFD delivery } \\
(n=287)\end{array}$} & \multirow[t]{2}{*}{$p$ value } & \multicolumn{2}{|c|}{ Term AFD delivery } & \multirow[t]{2}{*}{$p$ value } \\
\hline & & & & $\begin{array}{l}\text { Primipara } \\
(n=141)\end{array}$ & $\begin{array}{l}\text { Multipara } \\
(n=146)\end{array}$ & \\
\hline \multirow[t]{2}{*}{ Maternal age (years) } & $31.8 \pm 5.1$ & $31.0 \pm 4.7$ & \multirow[t]{2}{*}{0.367} & $29.7 \pm 4.8$ & $32.2 \pm 4.3$ & \multirow[t]{2}{*}{$<0.001$} \\
\hline & $32.0[19-38]$ & $31.0[17-43]$ & & $29.0[17-43]$ & $33.0[21-42]$ & \\
\hline \multirow{2}{*}{$\begin{array}{l}\text { Number of previous } \\
\text { deliveries }\end{array}$} & $1.7 \pm 7.6$ & $1.6 \pm 7.4$ & \multirow[t]{2}{*}{0.993} & $1.0 \pm 0.0$ & $2.3 \pm 0.5$ & \multirow[t]{2}{*}{$<0.001$} \\
\hline & $2.0[1-4]$ & $2.0[1-5]$ & & $1.0[1-1]$ & $2.0[2-5]$ & \\
\hline Prenatal hospitalization & $12(38.7 \%)$ & $42(14.7 \%)$ & 0.002 & $17(12.1 \%)$ & $25(17.2 \%)$ & 0.245 \\
\hline Cesarean section & $14(45.2 \%)$ & $39(13.6 \%)$ & $<0.001$ & $21(14.9 \%)$ & $18(12.3 \%)$ & 0.606 \\
\hline \multirow{2}{*}{$\begin{array}{l}\text { Gestational age at birth } \\
\text { (weeks) }\end{array}$} & $37.1 \pm 2.0$ & $39.3 \pm 1.2$ & \multirow[t]{2}{*}{$<0.001$} & $39.5 \pm 1.1$ & $39.0 \pm 1.2$ & \multirow[t]{2}{*}{0.001} \\
\hline & $37.0[34-41]$ & $39.0[37-42]$ & & $40.0[37-42]$ & $39.0[37-41]$ & \\
\hline \multicolumn{7}{|l|}{ Sex of infant } \\
\hline Male & $15(48.4 \%)$ & $153(53.7 \%)$ & \multirow[t]{2}{*}{0.577} & $70(49.6 \%)$ & $83(57.6 \%)$ & \multirow[t]{2}{*}{0.192} \\
\hline Female & $16(51.6 \%)$ & $132(46.3 \%)$ & & $71(50.4 \%)$ & $61(42.4 \%)$ & \\
\hline \multicolumn{7}{|l|}{ Infant weight $(\mathrm{g})$} \\
\hline At birth & $2,323.1 \pm 270.8$ & $3,086.3 \pm 314.6$ & $<0.001$ & $3,079.2 \pm 319.0$ & $3,093.3 \pm 311.6$ & 0.705 \\
\hline 1-month checkup & $3,559.6 \pm 415.0$ & $4,203.4 \pm 481.4$ & $<0.001$ & $4,184.9 \pm 439.5$ & $4,221.1 \pm 519.6$ & 0.540 \\
\hline 4-month checkup & $6,288.5 \pm 709.3$ & $6,962.2 \pm 767.6$ & $<0.001$ & $6,960.8 \pm 808.3$ & $6,963.5 \pm 730.5$ & 0.716 \\
\hline \multicolumn{7}{|l|}{ Feeding method } \\
\hline Breast milk & $18(58.1 \%)$ & $183(64.4 \%)$ & \multirow[t]{3}{*}{0.669} & $86(61.4 \%)$ & $97(67.4 \%)$ & \multirow[t]{3}{*}{0.546} \\
\hline Formula & $6(19.4 \%)$ & $40(13.8 \%)$ & & $20(14.3 \%)$ & $19(13.2 \%)$ & \\
\hline Combined & $7(22.6 \%)$ & $62(21.4 \%)$ & & $34(24.3 \%)$ & $28(19.4 \%)$ & \\
\hline Feeds well & $21(70.0 \%)$ & $261(90.9 \%)$ & 0.002 & $126(89.4 \%)$ & $135(92.5 \%)$ & 0.239 \\
\hline
\end{tabular}

$L B W$ Low birth weight, $A F D$ appropriate-weight for date

Data are presented as the mean \pm standard deviation (SD). For "Number of previous deliveries" and "Gestational age at birth" the median plus the range in square parenthesis are also given

tionnaire or was the primary caregiver, if the infant was not 4 months old, if the infant was treated for an illness, or if the mother had multiple children. After exclusion, data from 318 mother-child pairs were analyzed. Data were assigned to one of two groups on the basis of the infant's characteristics: (1) the preterm and/or LBW group that included LBW $(<2,500 \mathrm{~g})$ or preterm delivery $(<37$ gestational weeks) infants; (2) the AFD group, that included term delivery AFD infants.

\section{Clinical features}

The rate of hospitalization during pregnancy and the rate of caesarean sections (CS) were significantly higher in the preterm and/or LBW group than in the term AFD group. Infant weight was significantly lower in the preterm and/or LBW group at both the 1- and 4-month checkups (Table 1). While no significant differences were observed between feeding methods, the answer "infant is feeding well" was significantly less common in the preterm and/or LBW group than in the term AFD group. When primiparous and multiparous mothers were compared in the term AFD group, the birth dates of infants born to primiparous mothers were significantly later than those of infants born to multiparous mothers.

\section{Social characteristics}

Unwanted pregnancies were significantly more common in the preterm and/or LBW group (Table 2) than in the term AFD group. No significant differences were noted between the groups in terms of husband support during pregnancy, family composition, number of children, employment status, and household annual income. Household income was significantly higher for multiparous mothers than for primiparous mothers.

\section{Child-rearing anxiety and psychological stress}

Scores for the mother's feeling of child-rearing difficulty and a difficult baby, as well as dysfunctional family scores, were significantly higher in the preterm and/or LBW group (Table 3) than in the term AFD group.

Compared to the term AFD group, the preterm and/or LBW group reported the items "Husband takes good care 
Table 2 Social background of responders

\begin{tabular}{|c|c|c|c|c|c|c|}
\hline \multirow{2}{*}{$\begin{array}{l}\text { Characteristics relating } \\
\text { to social background }\end{array}$} & \multirow{2}{*}{$\begin{array}{l}\text { Preterm/LBW } \\
\text { delivery }(n=31)\end{array}$} & \multirow{2}{*}{$\begin{array}{l}\text { Term AFD } \\
\text { delivery }(n=287)\end{array}$} & \multirow[t]{2}{*}{$p$ value } & \multicolumn{2}{|c|}{ Term AFD delivery } & \multirow[t]{2}{*}{$p$ value } \\
\hline & & & & $\begin{array}{l}\text { Primipara } \\
(n=141)\end{array}$ & $\begin{array}{l}\text { Multipara } \\
(n=146)\end{array}$ & \\
\hline \multicolumn{7}{|l|}{ Unwanted pregnancy } \\
\hline Yes & $1(3.2 \%)$ & $8(2.8 \%)$ & 0.023 & $3(2.1 \%)$ & $5(3.4 \%)$ & 0.525 \\
\hline Not sure & $10(32.3 \%)$ & $39(13.6 \%)$ & & $22(15.6 \%)$ & $17(11.7 \%)$ & \\
\hline No & $20(64.5 \%)$ & $239(83.6 \%)$ & & $116(82.3 \%)$ & $123(84.9 \%)$ & \\
\hline \multicolumn{7}{|c|}{ Support from husband during pregnancy } \\
\hline Yes & $25(80.6 \%)$ & $246(85.7 \%)$ & 0.654 & $116(82.2 \%)$ & $130(89.8 \%)$ & 0.210 \\
\hline Not sure & $4(12.9 \%)$ & $31(10.8 \%)$ & & $18(12.8 \%)$ & $18(12.4 \%)$ & \\
\hline No & $2(6.5 \%)$ & $10(3.5 \%)$ & & $7(5.0 \%)$ & $7(4.8 \%)$ & \\
\hline \multicolumn{7}{|l|}{ Family composition } \\
\hline Nuclear family & $23(74.2 \%)$ & $247(86.7 \%)$ & 0.102 & $119(84.4 \%)$ & $128(88.9 \%)$ & 0.298 \\
\hline Extended family & $8(25.8 \%)$ & $38(13.3 \%)$ & & $22(15.6 \%)$ & $16(11.1 \%)$ & \\
\hline Number of children & $1.6 \pm 0.7$ & $1.6 \pm 0.7$ & 0.881 & $1.0 \pm 1.9$ & $2.2 \pm 0.5$ & $<0.001$ \\
\hline & $2.0[1-4]$ & $2.0[1-4]$ & & $1.0[1-3]$ & $2.0[1-4]$ & \\
\hline \multicolumn{7}{|l|}{ Siblings } \\
\hline Yes & $16(51.6 \%)$ & $145(50.7 \%)$ & 1.000 & $2(1.4 \%)$ & $143(98.6 \%)$ & $<0.001$ \\
\hline No & $15(48.4 \%)$ & $141(49.3 \%)$ & & $139(98.6 \%)$ & $2(1.4 \%)$ & \\
\hline \multicolumn{7}{|l|}{ Employment status } \\
\hline Homemaker & $20(64.5 \%)$ & $167(58.6 \%)$ & 0.654 & $83(58.9 \%)$ & $84(58.3 \%)$ & 0.934 \\
\hline On maternity leave & $9(29.0 \%)$ & $105(36.8 \%)$ & & $51(36.1 \%)$ & $54(37.5 \%)$ & \\
\hline Working & $2(6.5 \%)$ & $13(4.6 \%)$ & & $7(5.0 \%)$ & $6(4.2 \%)$ & \\
\hline \multicolumn{7}{|c|}{ Annual income (in million yen) } \\
\hline$<2$ & $1(3.8 \%)$ & $12(4.3 \%)$ & 0.932 & $12(8.6 \%)$ & $0(0.0 \%)$ & 0.007 \\
\hline 2 to $\leq 4$ & $14(53.9 \%)$ & $123(44.7 \%)$ & & $63(45.0 \%)$ & $60(44.2 \%)$ & \\
\hline 4 to $\leq 6$ & $9(34.7 \%)$ & $97(35.2 \%)$ & & $44(31.4 \%)$ & $53(39.0 \%)$ & \\
\hline 6 to $\leq 8$ & $1(3.8 \%)$ & $26(9.4 \%)$ & & $15(10.7 \%)$ & $11(8.1 \%)$ & \\
\hline 8 to $\leq 10$ & $1(3.8 \%)$ & $12(4.3 \%)$ & & $5(3.6 \%)$ & $7(5.1 \%)$ & \\
\hline 10 to $\leq 12$ & $0(0.0 \%)$ & $4(1.4 \%)$ & & $0(0.0 \%)$ & $4(2.9 \%)$ & \\
\hline 12 to $\leq 14$ & $0(0.0 \%)$ & $2(0.7 \%)$ & & $1(0.7 \%)$ & $1(0.7 \%)$ & \\
\hline
\end{tabular}

Data are presented as the mean $\pm \mathrm{SD}$; for "Number of children, the median plus the range in square parenthesis are also given

of our child and myself," "I am glad I married this person," and "my husband is happy" at a significantly lower frequency and the items "our household doesn't function well" and "my husband doesn't actively get involved in housework or child-rearing" at a significantly higher frequency. Answers such as "I don't know what to do for my child" and "I don't quite understand the daily rhythm of my child" were also significantly more common in the preterm and/or LBW group than in the term AFD group.

In the term AFD group, primiparous mothers answered with significantly higher scores for a difficult baby than multiparous mothers. However, multiparous mothers reported significantly higher dysfunctional family scores. No significant difference was observed between primiparous and multiparous mothers in terms of the presence of someone to discuss childcare with and/or to help with child-rearing.

Our evaluation of psychological stress revealed that psychological stress was lower during hospitalization and higher during pregnancy and at 2-3 days after discharge in both the preterm and/or LBW and term AFD groups. However, we observed no significant differences between groups for any of these periods. Within the term AFD group, primiparous mothers showed the highest psychological stress scores from discharge to the 1-month checkup. In contrast, multiparous mothers showed the highest psychological stress scores during pregnancy. During hospitalization after delivery, during the 2-3 days after discharge, and from that time until the 1-month checkup, psychological stress scores were significantly higher in primiparous mothers than in multiparous mothers. 
Table 3 Factors related to child-rearing anxiety and stress state

\begin{tabular}{|c|c|c|c|c|c|c|}
\hline \multirow{2}{*}{$\begin{array}{l}\text { Factors related to child-rearing } \\
\text { anxiety and stress state }\end{array}$} & \multirow{2}{*}{$\begin{array}{l}\text { Preterm/ILBW } \\
\text { delivery }(n=31)\end{array}$} & \multirow{2}{*}{$\begin{array}{l}\text { Term AFD } \\
\text { delivery }(n=286)\end{array}$} & \multirow[t]{2}{*}{$p$ value } & \multicolumn{2}{|c|}{ Term AFD delivery } & \multirow[t]{2}{*}{$p$ value } \\
\hline & & & & $\begin{array}{l}\text { Primipara } \\
(n=140)\end{array}$ & $\begin{array}{l}\text { Multipara } \\
(n=146)\end{array}$ & \\
\hline \multicolumn{7}{|c|}{ Factors related to child-rearing anxiety (JCFRI) } \\
\hline Child-rearing anxiety & $20.0[13-37]$ & $20.0[11-42]$ & 0.410 & $19.5[11-42]$ & $20.0[11-38]$ & 0.402 \\
\hline Feeling of child-rearing difficulty & $18.5[11-27]$ & $17.0[8-28]$ & 0.018 & $16.5[8-28]$ & $17.0[8-28]$ & 0.321 \\
\hline Difficult baby & $13.5[8-35]$ & $12.0[8-28]$ & 0.048 & $12.0[8-28]$ & $11.0[8-24]$ & 0.001 \\
\hline Family function & $42.0[26-78]$ & $37.0[25-80]$ & 0.095 & $34.5[25-78]$ & $38.0[25-80]$ & 0.023 \\
\hline \multicolumn{7}{|l|}{ Stress } \\
\hline During pregnancy & $5.0[0-10]$ & $5.3[0-10]$ & 0.738 & $5.0[0-10]$ & $6.0[0-10]$ & 0.120 \\
\hline During hospitalization & $3.0[0-9]$ & $3.0[0-10]$ & 0.510 & $4.0[0-10]$ & $3.0[0-10]$ & 0.010 \\
\hline 2-3 days after discharge & $5.0[0-10]$ & $5.0[0-10]$ & 0.198 & $5.3[0-10]$ & $4.0[0-10]$ & 0.025 \\
\hline Until 1-month checkup & $4.0[0-10]$ & $5.0[0-10]$ & 0.214 & $6.0[0-10]$ & $5.0[0-10]$ & 0.022 \\
\hline At present & $4.0[0-9]$ & $4.0[0-10]$ & 0.533 & $3.0[0-10]$ & $4.0[0-10]$ & 0.448 \\
\hline
\end{tabular}

JCFRI Japan Child and Family Research Institute Child Rearing Support Questionnaire

Data are presented as the median with the range in square brackets

Table 4 Developmental state according to preterm or term delivery and primipara or multipara

\begin{tabular}{lcccccc}
\hline Developmental state & $\begin{array}{l}\text { Preterm/LBW } \\
\text { delivery }(n=31)\end{array}$ & $\begin{array}{c}\text { Term AFD } \\
\text { delivery }(n=286)\end{array}$ & $p$ value & \multicolumn{2}{c}{ Term AFD delivery value } \\
\cline { 5 - 6 } & & & $\begin{array}{l}\text { Primipara } \\
(n=140)\end{array}$ & $\begin{array}{l}\text { Multipara } \\
(n=146)\end{array}$ \\
\hline Development (KIDS) & & & & & \\
$\quad$ Motor score & $10.0[5-12]$ & $10.0[2-13]$ & 0.240 & $10.0[2-13]$ & $10.0[4-13]$ & 0.326 \\
Motor skills & $9.0[5-12]$ & $11.0[3-14]$ & 0.001 & $11.0[6-14]$ & $10.0[3-14]$ & 0.001 \\
Language comprehension & $6.0[1-8]$ & $7.0[1-8]$ & 0.031 & $7.0[1-8]$ & $7.0[2-8]$ & 0.466 \\
Verbalization & $6.0[3-8]$ & $6.0[2-8]$ & 0.950 & $6.0[3-8]$ & $6.0[2-8]$ & 0.054 \\
Sociability with adults & $12.0[4-16]$ & $13.0[6-19]$ & 0.153 & $14.0[6-19]$ & $12.0[6-19]$ & 0.002 \\
Diet & $4.0[1-6]$ & $4.0[0-7]$ & 0.143 & $4.0[0-7]$ & $4.0[1-7]$ & 0.470 \\
\hline
\end{tabular}

KIDS Kinder Infant Development Scale test

Data are presented as the median with the range in square brackets

Development of infants based on KIDS score

With regard to the KIDS scores, motor skills and language comprehension scores were significantly lower in the preterm and/or LBW group than in the term AFD group. No significant differences were observed for any of the other items (Table 4).

Various factors associated with development (KIDS) in the term AFD group

Infant development and related factors were investigated within the term AFD group.

Parity In the term AFD group, scores for motor skills and sociability with adults were significantly higher for infants born to primiparous mothers than for those born to multiparous mothers, while verbalization scores also tended to be higher in the former [mean \pm standard deviation (SD); $6.3 \pm 1.4$ vs. $5.9 \pm 1.6$, respectively]. No significant differences were observed between groups for any of the other items (Table 4).

Maternal age Infants born to mothers who were in their 40s had significantly higher verbalization scores than those born to mothers in their $20 \mathrm{~s}$ or 30 s (Table 5). The proportion of primiparous mothers in their 20s, 30s, and $40 \mathrm{~s}$ was 66,37 , and $70 \%$, respectively. There was no significant difference between the proportion of primiparous mothers in their 40s and 20s; however, the proportion of primiparous mothers in their 30 s was lower than that in the other two age groups.

Type of delivery Infants born by CS had significantly lower diet scores than those born normally by vaginal delivery ( $3.8 \pm 1.3$ vs. $4.3 \pm 1.4$, respectively); motor 
Table 5 Comparison of 4-month-old infant development according to maternal age group

\begin{tabular}{|c|c|c|c|c|c|c|}
\hline \multirow[t]{2}{*}{ Development item (KIDS) } & \multicolumn{6}{|l|}{ Maternal age } \\
\hline & Teens $(n=2)^{\mathrm{a}}$ & $20 \mathrm{~s}(n=106)^{\mathrm{b}}$ & $30 \mathrm{~s}(n=165)^{\mathrm{c}}$ & $40 \mathrm{~s}(n=10)^{\mathrm{d}}$ & $p$ value & Post hoc \\
\hline Motor score & $11.0[10-12]$ & $10.0[2-13]$ & $10.0[4-13]$ & $10.5[6-11]$ & 0.752 & \\
\hline Motor skills & $10.5[9-12]$ & $11.0[6-14]$ & $10.0[5-14]$ & $11.5[9-14]$ & 0.444 & \\
\hline Language comprehension & $5.5[5-6]$ & $7.0[1-8]$ & $7.0[2-8]$ & $7.0[4-8]$ & 0.577 & \\
\hline Verbalization & $7.5[7-8]$ & $6.0[3-8]$ & $6.0[2-8]$ & $7.5[5-8]$ & 0.037 & $\mathrm{~b}$ and $\mathrm{d}^{*}, \mathrm{c}$ and $\mathrm{d}^{*}$ \\
\hline Sociability with adults & $9.0[6-12]$ & $13.0[8-17]$ & $13.0[6-18]$ & $13.5[10-19]$ & 0.217 & \\
\hline Diet & $4.0[4-6]$ & $4.0[2-7]$ & $4.0[0-7]$ & $4.0[2-7]$ & 0.819 & \\
\hline
\end{tabular}

$* p<0.05$

Data are presented as the median with the range in square brackets

Maternal age

${ }^{\mathrm{a}}$ Teens

b 20 s

c $30 \mathrm{~s}$

d $40 \mathrm{~s}$

Table 6 Comparison of 4-month-old infant development according to delivery circumstances

\begin{tabular}{|c|c|c|c|c|c|c|c|c|c|c|}
\hline \multirow{2}{*}{$\begin{array}{l}\text { Development } \\
\text { item (KIDS) }\end{array}$} & \multicolumn{2}{|l|}{ Type of delivery } & \multirow[t]{2}{*}{$p$ value } & \multicolumn{3}{|c|}{ Was it a difficult delivery? } & \multirow[t]{2}{*}{$p$ value } & \multicolumn{2}{|l|}{ Sex of infant } & \multirow[t]{2}{*}{$p$ value } \\
\hline & $\begin{array}{l}\text { Normal vaginal } \\
\text { delivery } \\
(n=248)\end{array}$ & $\begin{array}{l}\text { Caesarean } \\
\text { section } \\
(n=39)\end{array}$ & & $\begin{array}{l}\text { Yes } \\
(n=189)\end{array}$ & $\begin{array}{l}\text { Neither } \\
(n=45)\end{array}$ & $\begin{array}{l}\text { No } \\
(n=51)\end{array}$ & & $\begin{array}{l}\text { Male } \\
(n=153)\end{array}$ & $\begin{array}{l}\text { Female } \\
(n=132)\end{array}$ & \\
\hline Motor score & $10.0[2-13]$ & $10.0[4-13]$ & 0.451 & $10.0[2-13]$ & $10.0[5-13]$ & $10.0[4-12]$ & 0.478 & $10.0[4-13]$ & $10.0[2-13]$ & 0.533 \\
\hline Motor skills & $11.0[5-14]$ & $10.0[3-14]$ & 0.076 & $11.0[3-14]$ & $11.0[6-14]$ & $10.0[5-14]$ & 0.571 & $11.0[5-14]$ & $11.0[3-14]$ & 0.251 \\
\hline $\begin{array}{l}\text { Language } \\
\text { comprehension }\end{array}$ & $7.0[2-8]$ & $6.0[1-8]$ & 0.172 & $7.0[1-8]$ & $7.0[2-8]$ & $7.0[2-8]$ & 0.32 & $7.0[2-8]$ & $7.0[1-8]$ & 0.236 \\
\hline Verbalization & $6.0[2-9]$ & $6.0[3-8]$ & 0.718 & $6.0[3-8]$ & $6.0[3-8]$ & $6.0[2-9]$ & 0.787 & $6.0[2-9]$ & $6.0[2-8]$ & 0.533 \\
\hline $\begin{array}{l}\text { Sociability with } \\
\text { adults }\end{array}$ & $13.0[6-19]$ & $12.0[6-18]$ & 0.300 & $13.0[6-18]$ & $13.0[6-17]$ & $12.0[8-19]$ & 0.297 & $13.0[6-19]$ & $13.0[6-19]$ & 0.847 \\
\hline Diet & $4.0[0-7]$ & $4.0[1-7]$ & 0.033 & $4.0[0-7]$ & $4.0[1-7]$ & $4.0[1-7]$ & 0.758 & $4.0[1-7]$ & $4.0[0-7]$ & 0.895 \\
\hline
\end{tabular}

Data are presented as the median with the range in square brackets

skill scores also tended to be lower in the former group (Table 6). No other significant relationships were observed between type of delivery and scores for any of the other items.

Fatigue at delivery No significant relationships were observed between fatigue at delivery and scores for the other items (Table 6).

Sex of infant No significant relationships were observed between infant sex and scores for the other items (Table 6).

Type of feeding Exclusively breast-fed infants had significantly higher language comprehension scores than formula-fed or combined breast-fed-formula-fed infants; motor skill scores also tended to be higher in the former than in the latter group (Table 7). No other significant relationships were observed between feeding method and scores for any of the other items.

Household lifestyle At 4 months after birth, infants born to working mothers had significantly higher verbalization scores than those born to nonworking mothers (Table 8). No significant relationships were observed between household income or satisfaction with current lifestyle and scores for any of the other items.

Family No significant differences were observed between those living with nuclear families and those living with extended families (Table 9). Compared with infants with no siblings or those with siblings aged $\geq 5$ years, infants with siblings aged $<4$ years exhibited significantly lower motor skill scores, verbalization scores $(6.3 \pm 1.4$ vs. $5.7 \pm 1.6$, respectively), and scores for sociability with adults. 
Table 7 Comparison of 4-month-old infant development according to infant feeding state

\begin{tabular}{|c|c|c|c|c|c|c|c|c|}
\hline \multirow{2}{*}{$\begin{array}{l}\text { Development item } \\
\text { (KIDS) }\end{array}$} & \multicolumn{4}{|c|}{ Feeding method } & \multirow[t]{2}{*}{$p$ value } & \multicolumn{2}{|l|}{ Suckling } & \multirow[t]{2}{*}{$p$ value } \\
\hline & $\begin{array}{l}\text { Breast milk } \\
(n=183)^{\mathrm{a}}\end{array}$ & $\begin{array}{l}\text { Formula } \\
(n=39)^{\mathrm{b}}\end{array}$ & $\begin{array}{l}\text { Combined } \\
(n=62)^{\mathrm{c}}\end{array}$ & Post hoc & & $\begin{array}{l}\text { Good } \\
(n=261)\end{array}$ & $\begin{array}{l}\text { Irregular } \\
(n=26)\end{array}$ & \\
\hline Motor score & 10.0 [4-13] & $9.0[5-13]$ & $10.0[2-12]$ & & 0.132 & $10.0[4-13]$ & $9.5[2-13]$ & 0.365 \\
\hline Motor skills & 11.0 [6-14] & $10.0[6-13]$ & $10.5[5-14]$ & & 0.058 & 11.0 [3-14] & 10.0 [7-14] & 0.579 \\
\hline $\begin{array}{l}\text { Language } \\
\text { comprehension }\end{array}$ & $7.0[2-8]$ & $6.0[2-8]$ & $6.0[1-8]$ & $\begin{array}{l}\mathrm{a} \text { and } \mathrm{b}^{* *}, \mathrm{a} \\
\text { and } \mathrm{c}^{*}\end{array}$ & 0.005 & $7.0[2-8]$ & $6.5[1-8]$ & 0.381 \\
\hline Verbalization & $6.0[3-8]$ & $6.0[3-8]$ & $6.5[2-8]$ & & 0.264 & $6.0[3-8]$ & $6.0[2-8]$ & 0.164 \\
\hline $\begin{array}{l}\text { Sociability with } \\
\text { adults }\end{array}$ & 13.0 [6-19] & $12.0[7-18]$ & 13.0 [6-19] & & 0.265 & 13.0 [6-19] & $12.5[8-17]$ & 0.165 \\
\hline Diet & $4.0[0-7]$ & $4.0[1-7]$ & $4.0[2-7]$ & & 0.639 & $4.0[0-7]$ & $4.0[1-7]$ & 0.675 \\
\hline
\end{tabular}

$* p<0.05, * * p<0.01$

Data are presented as the median with the range in square brackets

Feeding method

${ }^{\text {a }}$ Breast milk

b Formula milk

${ }^{\mathrm{c}}$ Combined breast milk and formula milk

Analysis of factors that strongly influence 4-month-old infant development Multiple regression analysis was used to evaluate the influence of background factors on each item of the development score. The results showed the following: [Motor score] $=-0.068 \chi^{1}$ [feeling of child-rearing difficulty scale] +10.798 ; [Motor skill score] $=0.807 \chi^{1}$ [sibling age] $-0.067 \chi^{2}$ [feeling of child-rearing difficulty scale] $+0.251 \chi^{3} \quad$ [gestational weeks at birth] + $0.471 \chi^{4}$ [feeding method] +0.855 ; [Language comprehension score $]=0.586 \chi^{1}$ [feeding method] +5.970 ;

[Verbalization score] $=0.585 \chi^{1} \quad$ [sibling's age $0.052 \chi^{2} \quad$ [feeling of child-rearing difficulty scale $]+0.969 \chi^{3}$ [maternal age $]+6.562$; [Sociability with adults score $]=1.024 \chi^{1}$ [sibling's age] $-0.071 \chi^{2}$ [feeling of child-rearing difficulty scale] +13.363 ; [Diet score $]=-0.059 \chi^{1} \quad$ [feeling of child-rearing difficulty scale] $+0.159 \chi^{2}$ [gestational weeks at birth] -1.061 .

\section{Discussion}

In this study, we examined six items that can be used to assess the development of 4-month-old infants and found significant correlations for each item. Previous studies have demonstrated that many factors can affect the physical and mental development of children. In two separate studies, postpartum depression was found to affect emotional development in 5-year-old children [18] and cognitive development in 3 -year-old children [19]. In another study involving 4-year- old children, maternal antenatal anxiety was found to affect the child's emotional development and was associated with behavioral issues such as inattention, hyperactivity, and conduct problems [20]. Maternal smoking during pregnancy has been related to impaired cognitive development [21]. In a study on 2-year-old children, Gómez-Sanchiz et al. reported that the parents' educational background and family's social class were related to the child's mental development [22]. Developmental delays in 1-year-old children (12-18 months) have been reported to be correlated with maternal depression during pregnancy [23]. Breast-feeding has been found to affect mental development in 12- and 14-month-old children [24, 25] and mother and child interactions have been observed to influence the child's socioemotional development [8]. Buitelaar et al. found that maternal anxiety and depression during the third trimester of pregnancy were related to delayed mental development in 8-month-old infants [26]. Taken together, the results of these studies indicate that maternal condition, both during pregnancy and after childbirth, together with the child's home environment, influence child development.

In our study, we evaluated the development of 4-monthold infants. Early evaluation of development in infants and implementation of appropriate measures when problems are detected can improve subsequent development. At the present time in Japan, infants undergo a health checkup at 4 months. We believe that research on infants during this period can provide highly significant results that can be of use in developing government initiatives. 


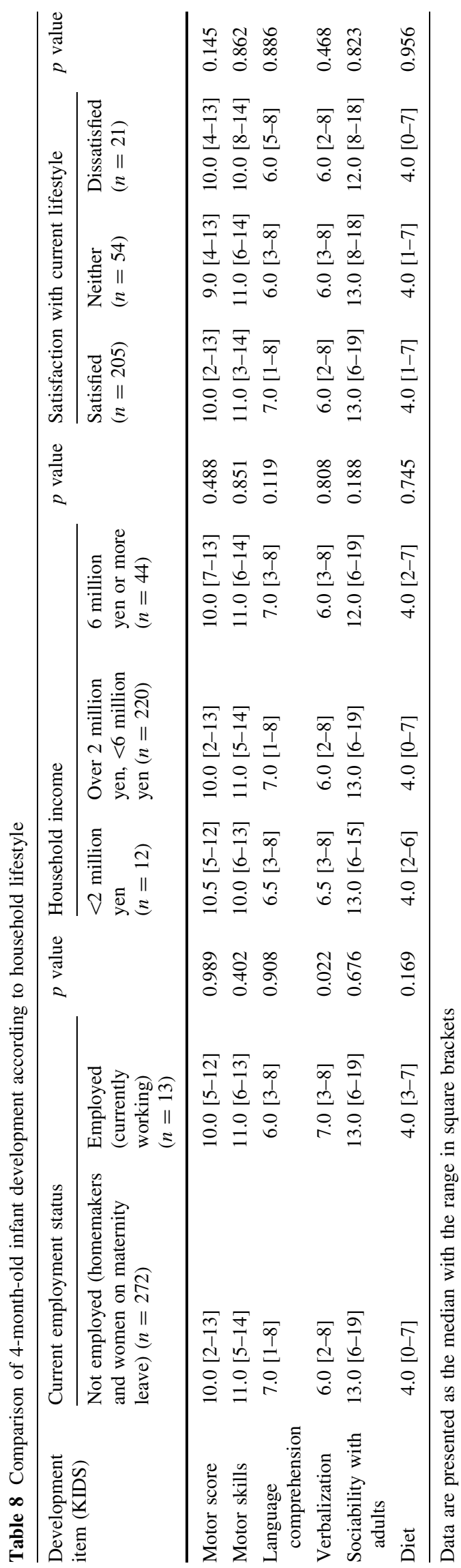

In their study of 4-month-old infants, Davis et al. reported that maternal anxiety and depressive state during the third trimester were related to the mother's reactions to infant behavior [27] and that the mother's expressions during mother-infant interactions influence subsequent emotional development [28]. Another study reported that in 3-month-old infants, prenatal stress was related to the infant's mental and psychomotor development as well as temperament [26]. However, only mental and developmental milestones in infants were investigated in these studies, and developmental delays were overlooked. Therefore, in our study we focused on developmental delays using the KIDS test and comprehensively evaluated scores for both behavioral and mental development.

\section{Preterm and/or LBW infants}

In our study we compared the development of 4-month-old infants (nonadjusted age) with LBW and/or preterm birth with that of term infants. We found that LBW and preterm birth infants had lower KIDS test scores for motor skills and language comprehension development. Developmental problems have been found to be common in LBW and/or preterm birth infants $[16,17]$. This may be due to a LBW or complications in neural development while in the womb or during delivery which influence development [29] and lead to respiratory complications, such as chronic respiratory tract disease or asthma [30] or cardiovascular disturbances [31]. In addition, greater maternal parenting stress has been reported to lead to diminished communication skills in 3-month-old preterm infants [32]. Therefore, even when there is no problem in the preterm infant, mothers and/or the child-rearing environment may influence subsequent child development.

The results of our study indicate that prenatal hospitalization and a CS delivery were more common in mothers of LBW and/or preterm infants than in mothers of term AFD infants. Maternal prenatal hospitalization may cause posttraumatic stress symptoms in mothers that can lower the quality of parent-infant interactions. The rate of postpartum depression is known to be higher in mothers who undergo CS than in mothers that undergo vaginal delivery [33] and that this postpartum depression may lead to poor mother-child attachment. Furthermore, environmental factors during the infant's hospitalization can also lead to poor mother-child attachment, which may exert adverse effects on the infant's development.

In our study, mothers of LBW and/or preterm infants had significantly higher scores for both the difficult baby and feeling of child-rearing difficulty subscales compared with mothers of term AFD infants. Past studies have also reported that mothers of preterm birth infants are 
Table 9 Comparison of 4-month-old infant development according to family composition

\begin{tabular}{|c|c|c|c|c|c|c|c|c|}
\hline \multirow{2}{*}{$\begin{array}{l}\text { Development item } \\
\text { (KIDS) }\end{array}$} & \multicolumn{2}{|c|}{ Family composition } & \multirow[t]{2}{*}{$p$ value } & \multicolumn{3}{|l|}{ Siblings } & \multirow[t]{2}{*}{$p$ value } & \multirow[t]{2}{*}{ Post hoc } \\
\hline & $\begin{array}{l}\text { Nuclear family } \\
(n=247)\end{array}$ & $\begin{array}{l}\text { Extended family } \\
(n=38)\end{array}$ & & $\begin{array}{l}\text { None }^{\mathrm{a}} \\
(n=141)\end{array}$ & $\begin{array}{l}<4 \text { years }^{\mathrm{b}} \\
(n=108)\end{array}$ & $\begin{array}{l}\geq 5 \text { years }{ }^{c} \\
(n=35)\end{array}$ & & \\
\hline Motor score & $10.0[2-13]$ & $10.0[4-13]$ & 0.503 & $10.0[2-13]$ & $10.0[4-13]$ & $10.0[6-13]$ & 0.656 & \\
\hline Motor skills & $11.0[5-14]$ & $10.0[6-14]$ & 0.898 & $11.0[6-14]$ & $10.0[5-14]$ & $11.0[7-14]$ & 0.001 & $\begin{array}{l}\mathrm{a} \text { and } \mathrm{b}^{* * *}, \mathrm{~b} \\
\text { and } \mathrm{c}^{*}\end{array}$ \\
\hline $\begin{array}{l}\text { Language } \\
\text { comprehension }\end{array}$ & $7.0[1-8]$ & $6.0[3-8]$ & 0.485 & $7.0[1-8]$ & $7.0[2-8]$ & $7.0[3-8]$ & 0.187 & \\
\hline Verbalization & $6.0[2-8]$ & $7.0[2-8]$ & 0.750 & $6.0[3-8]$ & $6.0[2-8]$ & $7.0[4-8]$ & 0.001 & $\begin{array}{l}\mathrm{a} \text { and } \mathrm{b}^{* *}, \mathrm{~b} \\
\text { and } \mathrm{c}^{* *}\end{array}$ \\
\hline $\begin{array}{l}\text { Sociability with } \\
\text { adults }\end{array}$ & $13.0[6-19]$ & $13.0[6-17]$ & 0.341 & $13.0[6-19]$ & $12.0[6-19]$ & $13.0[9-18]$ & 0.002 & $\begin{array}{l}\mathrm{a} \text { and } \mathrm{b}^{* *}, \mathrm{~b} \\
\text { and } \mathrm{c}^{* *}\end{array}$ \\
\hline Diet & $4.0[0-7]$ & $4.0[2-7]$ & 0.145 & $4.0[0-7]$ & $4.0[1-7]$ & $4.0[2-7]$ & 0.671 & \\
\hline
\end{tabular}

$* p<0.05, * * p<0.01, * * * p<0.001$

Data are presented as the median with the range in square brackets

Siblings

${ }^{\text {a }}$ None (a child without a sibling)

b $<4$ years (sibling of 4 years or younger)

$c \geq 5$ years (sibling of 5 years and upward)

susceptible to psychological stress for 2 years after delivery [20,28]. High maternal parenting stress can also lead to confused mother-child interactions [34] and exert adverse effects on recognition development in 18-month-old infants [35].

Other reports have confirmed a relationship between an unwanted pregnancy and LBW infants [36]. In our study, the rate of unwanted pregnancies was significantly higher among mothers of LBW and/or preterm infants than among mothers of term AFD infants. Furthermore, family dysfunction was more common among the former than among the latter, and marital relationships suffered when mothers felt dissatisfied with their husbands for not participating in daily household activities or child-rearing. These environmental factors may also influence infant development.

It appears that the presence or absence of background factors, such as unwanted pregnancy and family dysfunction, should be confirmed in mothers of LBW and/or preterm infants. Moreover, a mother's feelings of childrearing difficulty should be assessed early, and if a problem is detected, proactive intervention, such as a health consultation with a public health nurse or midwife, health guidance, and child-rearing support, should be provided.

Developmental risk factors in term infants

Our study identified several factors that influence the development of term AFD infants. These factors are discussed in the following sections.
Parity To date, no study has investigated the relationship between maternal parity and the development of 3- to 4-month-old infants. Our results show that infants born to primiparous mothers exhibited better development of motor skills, sociability with adults, and verbalization than those born to multiparous mothers. We also found that primiparous mothers more frequently experienced maternal child-rearing anxiety and mental stress and felt that childrearing was difficult; these feelings also have the potential to exert adverse effects on infant development. In particular, mental stress was common during hospitalization for the delivery, during the 2-3 days following discharge, and from discharge until the infant's 1-month health checkup.

However, our investigation of family function found that multiparous mothers more often answered "my husband is only involved in his work and hobbies" and were less likely to answer "my husband is happy." Therefore, multiparous mothers more often reported a poor relationship with their husband and had higher family dysfunction scores than primiparous mothers. The relatively poorer marital relationships and family dysfunction commonly seen in multiparous mothers may lead to decreased infant development scores. Therefore, we believe that support is not only necessary for mothers but also for couples and families as a whole. Moreover, multiparous mothers also experience high levels of mental stress during their first experience with childbirth, subsequently adjusting to child-rearing. Therefore, proactive support for mothers who find child-rearing difficult may help to promote the infant's development. 
Maternal age The infants of mothers in their 40s had better verbalization scores than those of mothers in their $20 \mathrm{~s}$ and $30 \mathrm{~s}$. Previous studies have also shown that increased maternal age at delivery contributes to higher naming vocabulary scores and lower strengths and difficulties scores (social and emotional difficulties) in 3- and 5-year-old children [37]. Furthermore, older mothers are better educated, have higher family incomes, are more often married, and have greater child well-being [37].

We also found that $100 \%$ of teen respondents, $65.0 \%$ of the respondents in their $20 \mathrm{~s}, 36.4 \%$ of respondents in their $30 \mathrm{~s}$, and $40.0 \%$ of respondents in their $40 \mathrm{~s}$ had an annual income of $<4$ million yen. Also, of the respondents in their teen, 20s, 30s, and 40s, 0, 96.2, 99.4, and $100 \%$, respectively, lived with a husband or partner. Therefore, there was a trend towards increased age indicating a higher annual income and a greater likelihood of living with a husband or partner. These factors are likely to exert favorable effects on verbal development in infants.

Maternal stress in late pregnancy Our study did not reveal any correlation between maternal mental stress and infant development scores. However, strong prenatal stress, as indicated by cortisol levels in late pregnancy [26], can delay both mental and motor development in 3- and 8-month-old infants. In our study, we asked mothers to self-evaluate their prenatal stress levels at 4 months postpartum, but this evaluation may not have been accurate. In the future, stress during late pregnancy should be prospectively evaluated using indicators such as biological markers in addition to self-evaluation.

Type of delivery We found that infants born by CS tended to exhibit delayed motor and diet development compared with infants born by vaginal delivery. Postpartum depression is more common with CS than with vaginal delivery [33], and CS delivery may influence mother-child attachment and infant development. However, in one study CS was shown to have no effect on intelligence or delayed motor development in 6- to 7-yearold children [38]. In the future, the subsequent development of infants with a tendency for delayed motor and diet development at 4 months should be monitored.

Fatigue at delivery No correlation between the presence or absence of maternal fatigue at delivery and infant development scores was found in our study. However, a study that examined mothers of 18-month-old children did find a relationship between the mother's fatigue throughout the first 18 months after birth and infant development [39]. This result suggests that long-term persistence of fatigue after birth may influence development throughout early childhood. Therefore, it may be necessary to evaluate fatigue at delivery and during the period following delivery and provide support to mothers with persistent fatigue to improve the child's development.

Feeding Infants fed exclusively breast milk exhibited significantly higher scores for language comprehension compared with formula-fed or combined breast-fed and formula-fed infants; they also tended to exhibit higher scores for motor skills. Past studies have shown that breastfed infants have significantly improved cognitive development compared with formula-fed infants and that these effects continue from 6 months to 15 years of age [40]. It was reported that long-chain polyunsaturated fatty acids, docosahexaenoic acid, and arachidonic acid, all found in breast milk, support neuron development [40]. Moreover, increased maternal responsiveness promoted by the infant's suckling [41] also has a favorable effect on infant development, and mothers who engage in breast-feeding are generally more educated than formula-feeding mothers [22]. This also may have a favorable effect on infant development.

Household lifestyle This study found that at 4 months after birth, the infants of working mothers had better verbalization development compared with infants of nonworking mothers. Working mothers in Japan are known to maintain child-rearing time by decreasing their workload and leisure time, even after returning to work after maternity leave [42]. Therefore, mother and infant contact time is maintained even if the mother is working. Furthermore, it is likely that working mothers regularly place infants in the care of a daycare center or their grandparents. Those environments may promote infant development. In support of this view, infants who spend long periods of time at daycare centers have been found to show a favorable cognitive development [43]. This result suggests that when mothers are not working, infants need to be introduced early to places such as playgroups, where they can be exposed early to relationships other than the motherchild relationship.

Family While no significant differences in infant development were observed between nuclear and extended families, we did observe that motor skills, verbalization, and sociability with adults were poorer in infants with siblings aged $<4$ years than in those infants without siblings or siblings aged $\geq 5$ years. One explanation for this difference is that mothers with another child aged $<4$ years are likely to be heavily involved in that child's care, thus decreasing the amount of time they spend on the newborn infant. This may exert an adverse influence on the development of motor skills, sociability with adults, and verbalization.

A high proportion of multiparous mothers in this study $(74.7 \%)$ had another child aged <4 years, 
possibly clarifying why among our respondents the infants of multiparous mothers exhibited significantly poorer development of motor skills, sociability with adults, and verbalization compared with primiparous mothers. The proportion of respondents in their 20s, 30 s, and 40 s with another child aged $<4$ years was $32.1,43.9$, and $10.0 \%$, respectively. Therefore, a significantly higher proportion of mothers in their $20 \mathrm{~s}$ and 30s had another child aged $<4$ years compared with mothers in their 40s. This could also be a factor underlying the poorer verbalization scores for infants born to mothers in their 20s and 30s than for those born to mothers in their $40 \mathrm{~s}$.

\section{Analysis of factors that strongly influence 4-month-old} infant development Multiple regression analysis in this study indicated that the feeling of experiencing difficulty in child-rearing, sibling age, gestational age at birth, feeding method, and maternal age range were factors strongly related to 4-month-old infant development. In particular, the maternal feeling of experiencing difficulty in childrearing was found to be related to many aspects of infant development and, therefore, needs to be objectively evaluated and the scale for its evaluation optimized. Furthermore, taking early evaluation and intervention into consideration, prevention should begin prenatally by means of awareness campaigns and education at obstetrician clinics. It is also very likely that assessment and support soon after childbirth could be effective.

The results of this study reveal that various factors exert adverse effects on infant development. Future studies should examine whether preventive measures that provide pregnant women and mothers with infants in handling these various factors has favorable effects on the child's subsequent development. As such, it is important that the 4-month-old infant checkup is used to assess overall infant development using the KIDS test and based on the mother's assessment. In this study, the recovery rate of questionnaires was relatively low. To apply our tests to every single 4-month-old infant, carefully selected questionnaires and KIDS test should be sent in advance of the checkup.

In the future, further studies are required for the evaluation of infant development soon after birth, at the 1-month-old infant health checkup, to enable earlier intervention.

Acknowledgments This work was supported by Japan Society for the Promotion of Science (JSPS) KAKENHI Grant Number 24792603, Grant-in-Aid for Young Scientists (B).

Conflict of interest We do not have a financial relationship with any organization.

\section{References}

1. Talge NM, Neal C, Glover V. Antenatal maternal stress and longterm effects on child neurodevelopment: how and why? J Child Psychol Psychiatry. 2007;48:245-61.

2. Field T, Diego M, Hernandez-Reifm M, Schanberg S, Kuhn C, Yando R, et al. Pregnancy anxiety and comorbid depression and anger: effects on the fetus and neonate. Depress Anxiety. 2003;17:140-51.

3. Windham GC, Zhang L, Gunier R, Croen LA, Grether JK. Autism spectrum disorders in relation to distribution of hazardous air pollutants in the San Francisco Bay area. Environ Health Perspect. 2006;114:1438-44.

4. Braun JM, Froehlich TE, Daniels JL, Dietrich KN, Hornung R, Auinger P, Lanphear BP. Association of environmental toxicants and conduct disorder in U.S. children: NHANES 2001-2004. Environ Health Perspect. 2008;116:956-62.

5. Sood B, Delaney-Black V, Covington C, Nordstrom-Klee B, Ager J, Templin T, et al. Prenatal alcohol exposure and childhood behavior at age 6 to 7 years: I. dose-response effect. Pediatrics. 2001;108:E34.

6. Walker SP, Wachs TD, Gardner JM, Lozoff B, Wasserman GA, Pollitt E, Carter JA. Child development: risk factors for adverse outcomes in developing countries. Lancet. 2007;369:145-57.

7. McGrath JM, Records K, Rice M. Maternal depression and infant temperament characteristics. Infant Behav Dev. 2008;31:71-80.

8. Cerezo MA, Pons-Salvador G, Trenado RM. Mother-infant interaction and children's socio-emotional development with high- and low-risk mothers. Infant Behav Dev. 2008;31:578-89.

9. Evans GW. Child development and the physical environment. Annu Rev Psychol. 2006;57:423-51.

10. Frankenberg WK, Dodds J, Archer P, Shapiro H, Bresnick B. The Denver II: a major revision and restandardization of Denver developmental screening test. Pediatrics. 1992;89:91-7.

11. Brazelton, TB, Nugent JK. The Neonatal Behavioural Assessment Scale. 3rd edn. Clinics in Developmental Medicine, vol. 137. MacKeith Press, London (distributed by Cambridge University Press). 1995.

12. Bayley N. Bayley scales of infant development. San Antonio, 2nd edn. The Psychological Corporation, Hardcourt Brace \& Co., San Diego. 1993.

13. Miyake K, Ohmura M, Takashima M, Yamauchi S, Hashimoto K. Kinder infant development scale manual: Hattatsukagaku Kenkyu Kyoiku Center, Tokyo. 1989 (in Japanese).

14. Hashimoto K, Matsui N, Yakuwa H, Miyamura K. Evaluation of the family-rated kinder infant development scale (KIDS) for disabled children. Jikeikai Med J. 2012;59:5-10 (in Japanese).

15. Cheng S, Maeda T, Yamagata Z, Tomiwa K, Yamakawa N, Japan Children's Study Group. Comparison of factors contributing to developmental attainment of children between 9 and 18 months. J Epidemiol. 2010;20:S452-8.

16. Caravale B, Tozzi C, Albino G, Vicari S. Cognitive development in low risk preterm infants at 3-4 years of life. Arch Dis Child Fetal Neonatal Ed. 2005;90:F474-9.

17. Hediger ML, Overpeck MD, Ruan WJ, Troendle JF. Birth weight and gestational age effects on motor and social development. Paediatr Perinat Epidemiol. 2002;16:33-46.

18. Murray L, Sinclair D, Cooper P, Ducournau P, Turner P, Stein A. The socio-emotional development of 5-year-old children of postnatally depressed mothers. J Child Psychol Psychiatry. 1999;40:1259-71.

19. Sharp D, Hay DF, Pawlby S, Schmücker G, Allen H, Kumar R. The impact of postnatal depression on boys' intellectual development. J Child Psychol Psychiatry. 1995;36:1315-36. 
20. O'Connor TG, Heron J, Golding J, Beveridge M, Glover V. Maternal antenatal anxiety and children's behavioural/emotional problems at 4 years. Report from the Avon Longitudinal Study of Parents and Children. Br J Psychiatry. 2002;180:502-8.

21. Julvez J, Ribas-Fitó N, Torrent M, Forns M, Garcia-Esteban R, Sunyer J. Maternal smoking habits and cognitive development of children at age 4 years in a population based birth cohort. Int $\mathbf{J}$ Epidemiol. 2007;36:825-32.

22. Gómez-Sanchiz M, Cañete R, Rodero I, Baeza JE, González JA. Influence of breast-feeding and parental intelligence on cognitive development in the 24-month-old child. Clin Pediatr (Phila). 2004;43:753-61.

23. Deave T, Heron J, Evans J, Emond A. The impact of maternal depression in pregnancy on early child development. BJOG Int J Obstet Gynaecol. 2008;115:1043-51.

24. Guxens M, Mendez MA, Moltó-Puigmartí C, Julvez J, GarcíaEsteban R, Forns J, et al. Breastfeeding, long-chain polyunsaturated fatty acids in colostrum, and infant mental development. Pediatrics. 2011;128:e880-9.

25. Eickmann SH, de Lira PI, Lima Mde C, Coutinho SB, Teixeira Mde L, Ashworth A. Breast feeding and mental and motor development at 12 months in a low-income population in northeast Brazil. Paediatr Perinatal Epidemiol 2007;21:129-37.

26. Buitelaar JK, Huizink AC, Mulder EJ, de Medina PG, Visser GH. Prenatal stress and cognitive development and temperament in infants. Neurobiol Aging. 2003;24[Suppl]:S53-60.

27. Davis EP, Snidman N, Wadhwa PD, Glynn LM, Schetter CD, Sandman CA. Prenatal maternal anxiety and depression predict negative behavioral reactivity in infancy. Infancy. 2004;6:319-31.

28. Pauli-Pott U, Mertesacker B. Affect expression in mother-infant interaction and subsequent attachment development. Infant Behav Dev. 2009;32:208-15.

29. Candelaria M, O’Connell M, Teti DM. Cumulative psychosocial and medical risk as predictors of early infant development and parenting stress in an African-American preterm sample. J Appl Dev Psychol. 2006;27:588-97.

30. Duijts L. Fetal and infant origins of asthma. Eur J Epidemiol. 2012;27:5-14.

31. Osmond C, Barker DJ. Fetal, infant, and childhood growth are predictors of coronary heart disease, diabetes, and hypertension in adult men and women. Environ Health Perspect. 2000;108[Suppl 3]:545-53.

32. Newnham CA, Milgrom J, Skouteris H. Effectiveness of a modified Mother-Infant Transaction Program on outcomes for preterm infants from 3 to 24 months of age. Infant Behav Dev. 2009;32:17-26.

33. Petrosyan D, Armenian HK, Arzoumanian K. Interaction of maternal age and mode of delivery in the development of postpartum depression in Yerevan, Armenia. J Affect Disord. 2011;135:77-81.

34. Schatz D, Harder D, Schatz M, Harden K, Chilingar L, Fox D, Hoffman C. The relationship of maternal personality characteristics to birth outcomes and infant development. Birth. 2000;27:25-32.

35. Brummelte S, Grunau RE, Synnes AR, Whitfield MF, PetrieThomas J. Declining cognitive development from 8 to 18 months in preterm children predicts persisting higher parenting stress. Early Human Dev. 2011;87:273-80.

36. Shah PS, Balkhair T, Ohlsson A, Beyene J, Scott F, Frick C. Intention to become pregnant and low birth weight and preterm birth: a systematic review. Matern Child Health J. 2011;15:205-16.

37. Sutcliffe AG, Barnes J, Belsky J, Gardiner J, Melhuish E. The health and development of children born to older mothers in the United Kingdom: observational study using longitudinal cohort data. Br Med J. 2012;345:18.

38. Khadem N, Khadivzadeh $\mathrm{T}$. The intelligence quotient of school aged children delivered by cesarean section and vaginal delivery. Iran J Nurs Midwifery Res. 2010;15:135-40.

39. Parks PL, Lenz ER, Milligan RA, Han HR. What happens when fatigue lingers for 18 months after delivery? J Obstet Gynecol Neonatal Nurs. 1999;28:87-93.

40. Anderson JW, Johnstone BM, Remley DT. Breastfeeding and cognitive development: a meta-analysis. Am J Clin Nutr. 1999;70:525-35.

41. Tharner A, Luijk MP, Raat H, Ijzendoorn MH, BakermansKranenburg MJ, Moll HA, et al. Breastfeeding and its relation to maternal sensitivity and infant attachment. J Dev Behav Pediatr. 2012;33:396-404.

42. Hasegawa Y. Adjustment of time allocation and daily emotional experience during the transition to the role of a working mother. ShinrigakuKenkyu. 2010;81:123-31 (in Japanese).

43. Sylva K, Stein A, Leach P, Barnes J, Malmberg LE, FCCC team. Effects of early child-care on cognition, language, and taskrelated behaviours at 18 months: an English study. Br J Dev Psychol. 2011;29:18-45. 